should understand that the transference of doctors from one town to another when they were well known by a whole native clientèle greatly annoys patients. These moves, which are for the most part quite unnecessary, are calculated to hinder the spread of European medicine among the natives.

To sum up: The French Protectorate in Morocco has already made great progress in the sanitation of the new French colony, but much still remains to be done. It is quite $c$ mpetent to accomplish the considerable task which will be its work " after th war."

\section{DN THE ORIGIN OF ELECTRIC CURRENTS LED OFF FROM THE HUMAN BODY, ESPECIALLY IN RELATION TO “ NERVE-LEAKS."}

By W. M. BAYLISS, M.A., D.Sc., F.R.S., PROFESSOR OF GENERAL PHYSIOLOGY in ONIVERSITY COLLEGE, LCNDON.

Dering the last two or three years certain theories pro. pounded by Mr. Arthur E. Baines have received considerable attention, and have been applied in practice by a number of medical men who have accepted these views. I propose to examine the scientific basis on which they are founded.

The basis of the system lies in the fact that, by leading off from different points of the body by means of silver electrodes, currents of various degrees of magnitude can be detected when the electrodes are connected to a very sensitıve galvanometer of high resistance. In a case of shell shock, for example, a particular area of skin may give a large deflection compared with that normally obtained by holding the electrodes in the hands. This is called a "nerve-leak," and is interpreted as an escape of "neuro-electricity," or "nerve energy," from a place where the insulation of the nerve fibres has broken down, similarly to what happens in a submarine telegraph cable.

In the first place, we must remember that the animal body does not contain any metallic conductors; the conduction of an electric current is of a different kind from that in a wire. We must examine therefore the possible sources of potential difference, giving rise to currents. in such methods as those used by $\mathrm{Mr}$. Baines.

The human body is a system of solids and liquids intermixed. The solids are, when dry, non-conductors, but become conductors when soaked with the solutions in which they are immersed. These liquids contain salts, and it is by means of the salts that the current is conveyed. Hence they were calied by Faraday "electrolytes."

How is this done? When salts are dissolved in water they are sulit up into two or more atoms or molecular groups which have electrical charges of opposite sign. These products of dissociation are known as "ions," and the unit electrical charge carried by an ion is called an "electron." Electrons do not exist in such solutions free from the chemical atoms with which they are combined. In Mr. Baines's book, Electropathology, ions and electrons are said to be identical, and this fundamental crror runs through the whole theory. Ions and not electrons are the source of electrical differences in the body and serve as the only means of conduction of electrical currents. This they do by their actual movement, conveying electricity much as a horse and cart carries stoues. Being actual material existences and non volatile, they do not escape from the surface of the body to the air; as we are told that "nerve-leaks" do. Mr. Baines holds that electrolytic dissociation of salts in water is accompanied by an actual disintegration of the atoms themselres, by which free electrons are formed, as in the case of radiun. No proof has ever been giveu that the salts actually present in the body do this. If it were so, the astonishing equivalence between the amount of energy supplied as food and that given out in various forms by the organism would not be obtained experimentally. This fact is one of the most significant resu'ts of modern physiology.

The body th refore is full of ions, but not of free electrons, anu any explanation of electrical differences must be on this basis.

As a first step, let us see what happens when two places on the surface of such a moist conductor as the body is are led off by silver electrodes. We will suppose that the trio places are at the samo potential, and this is most easily obtained experimentally by taking a dilute solution of sodium chloride and immersing the electrodes in it. Now, unless the two electrodes are not only of the same metal, but also have their surfaces in precisely the same physical and chemical state, there will be found to be a potential difference between them. The exact origin of this potential difference would take too long to explain, and it is a some. what difficult question, depending on the tendency of the ions of the electrode to pass into the solution or those of the solution to pass into the electrode; but in practise I have found it impossible to get two silver elec. trodes which are equipotential in salt solutions. I have taken the greatest care and spent much time in the attempt, but have never obtained less than 0.006 volt. This potential difference would give, with Mr. Baines's galvanometer through the ordinary dry skin, a deflection of just about the order of that regarded by him as the normal hand-to-hand effect. Since the deflection obtained by the use of such electrodes on the skin depends on the resistance of the circuit, if one of them be moved to a place where the skin is moist the deflection will be greater, and the greater deflection indicates no more than that the resistance is less. This is the first kind of " nerve-leak," and I would emphasize the fact that no test of the equipotentiality of the electrodes is made in Mr. Baines's practice. In any normal person it is quite easy to find areas where the skin is moist and to compare the se with drier places, and it is an omission that so few tests for "nerve-leaks" hare been made in normal cases.

The simple state of affairs just described, although always present, is, however, not the whole story. Since the source here is in the electrodes, it is plain that if they are reversed in position, so that the one previously on the right hand is changed to the left hand, and vice versa, the direction of the galvanometer deflection is unchanged, whereas if the galvanometer connexions are changed, without altering the position in the hands, the direction is reversed. This, indeed, is usually the case, but not always. In the latter case it is clear that there must be a source of potential difference in the skin itself, which overpowers that of the electrodes. This can only be in restigated by the use of electrodes which do not themselves produce a potential difference when in contact with the skin; in other words, the so called non pelarizable electrodes must be used. The contact with the skin is made by a salt solution similar to that of the tissues themselves. It is familiar to all physical chemists that such phenomena as those with which we are concerned can only be investigated by the use of such electrodes, but it is unnecessary to describe here the details of their construction. For the present purpose their more im. portant property is that they can be made equipotential, or rather the one electrode has a potential exactly equal and opposite to that of the other, so that in use they uive rise to no current. Mr. Baines gives a series of extraordinary objections to ther use, based on his view of the importance of static charges and inductive capacity in phenomena of electro-physiology. I shall have occasion to discuss this point presently, and will merely refer here to the instructive photograplis taken by Dr. Thomas Lewis with the string galvanometer, showing the distortions produced by metallic electrodes. They were published in the Proceedings of the Physiological Society in the Journal of Physiology, vol. 49, p. li.

The most obvious source of electrical changes in the skin is the activity of the sweat glands, long known to be accompanied by such effects. Moreover, Tarchanoff showed that all kinds of mental states produced localized activities of these glands. Shell shock and neurasthenic states are undoubtedly conditions of mental instability and easily induce activity of sweat glands. There may be also other sources of electrical changes in the skin in addition to this.

The explanation of electrical changes in cells is beyond the limit of this article; the most acceptable view is that they are due to the separation of the positive from the negative ions by the interposition of a membrane through which only one kind of the ions is able to pass. Thus we have a Helmholtz "double-layer" which can be best realized by the comparison of a field containing ewes and 
lambs separated from another field by a fence througl which oniy the lambs can pass. Just as the attraction between oppositely charged ions prevents either from leaving the membrane to any great distance, so the attraction of food and parental carc prevents both the ewes and the lambs from wandering very far from each other, although on one side of the fence the lambs will be in the majority, on the other side the ewes.

At one time I was inclined to think that these areas of localized sweating might be counecter in some way with Head's areas of referred pain, but further investigation showed that it was impossible to refer them to any definite lesions in the nerve centres.

We have, in any case, another lind of "nerve-lealk." of a more distinctly physiological origin. It is, when metallic electrodes are used, associated with the first kind, and the result on the galvanometer is the algebraical sum of the two together. Without any further hypothesis, they are capable of accounting for all the results. But Mr. Baines holds that these results are to be explained by static charges and "inductive capacity." I have made numerous attempts to detect the production of currents by giving charges to insulated bodies connected by electrodes to the galvanometer and have failed altogether. Indeed, since the points led off must be equipotential whaterer the magnitude of the charge given, it is difficult to see how currents could be produced. The charge, as Faraday showed, is situated on the surface and cannot affect processes going on in the interior of the body tissues. Static charge may, I hold, be rejected. What about "inductive capacity"? I found some difficulty in discovering how Mr. Baines imagines this to play a part. But, ultimately it turned ont to be this: The galvanometer deflection obtained from a patient is found to be very sensitive to the passing of electric trains, but, instead of looking for the cause in action upon the magnetic system, Mr. Baines attributes the deflection to currents induced in the human body which are being led off. This seems almost inconceivable in a skilled electrician, but no other evidence is given.

In Mr. Baines's theories there is a flow of what he calls "neuro-electricity" along nerves. This is stated to be a kind of ordinary electricity, so nearly the same that it passes as such around the coils of the galvanometer. If this be so, nerves, when cut and the ends placed in contact and insulated from the exterior, should conduct impulses, not of course giving rise to co-ordinate movements, but to movements of some kind. In point of fact, they do not, as is common knowledge. The source of this " neuroelectricity" is supposed to be the brain and by atomic dis. integration. No proof of any kind is given, and, whatever may be the nature of the nerve impulse, it is certain that there is no continuous stream of energy, and all that we know points to its being connected with the concentration of certain ions at membranes.

I pass on to the method of treatment founded on the theory of neuro-electricity. This is the application of "diclectric oil," or similar preparation, which are supposed to act as insulators and thus stop the leaks. Not only are the nerve-leaks of shell shock cured, but also all inflammatory states, such as preumonia and so forth. All living cells are stated to lose their "vitality" if deprived of their supply of nerve energy. That this is incorrect is shown in a striking way by the experiments of Clara Jacobson, who showed that wounds in a denervated limb heal quite as rapidly as those in a normal limb.

What is this "dielectric oil"? It is merely a good specimen of ordinary liquid paraffin; in fact, its insulating properties are rather inferior to those of a preparation which I obtained from Messis. Hoplin and Williams. I have made a detailed investigation of the chemical and physical properties of various paraffins, but was unable to find any possessed by the "dielectric oil" beyoud those of other commercial samples. More especially it is easy to show that it does not penetrate the skin. If it did so, the electrical resistance would rise. The electrical resistance loes not change. Further, the dielectric oil loses the greater part of its insulating power by contact with salt solutions, as it must be in the skin and tissues.

There is no doubt that liquid paraffin is a pleasant Mressing for raw wounds; it is protectice, and to some extent excludes infection by micro-organisms. But it has no effect on the resuits of general infection.
In the attempt to explain the curative results obtained, apart from those obviously due to suggestion, it is necessary to bear in mind the great difficulty of avoiding the fallacy of concluding that a phenomenon which follows another in time is the direct result of the former one. Thus, when the temperature in pneumonia falls after the application of "dielectric" to the front of the chest, how do we know that the temperature would not have fallen without the dielectric? In any case, I cannot accept it as a proof of penetration through the chest that the bedclothes beneath the patient were found soaked with paraffin three hours after its application to the front of the chest. It is rather remarliable that, in Mr. Baines's list of the important properties of his "dielectric," that of low surface tension is omitted.

In conclusion, I might say that it would be unjust to blame those medical men who have adopted the theories of Mr. Baines. 'They deal with a very complex branch of physiological science, although it is not so complex as $\mathrm{Mr}$. Baines would have it.

The net results of my investigations may be summed up thus :

1. Currents led off from various parts of the body by metallic electiodes are due to inequalities in the electrodes, together with differences in the activity of the skin glands.

2. Neither static charges nor induction plays any part.

3. "Nerve-lealss" are merely places where the skin is moist, and they give no indication of lesions in the nerve centres.

4. The view that " neuro-electricity" is generated in the brain and escapes from nerves owing to breakdown of insulation is devoid of evidence and contrary to the knowledge we possess of physiological processes.

5. My examination of Baines's "dielectric oil " leads me to conclude that it is ordinary liquid paraftin; that it does not pass through the skin and cannot reach any nerve or other internal tissue.

6. Treatment of open wounds by liquid paraffin has some justification in excluding air and perhaps bacterial infection. But it is not new. The results obtained have no relation to insulating properties, and the "dielectric" has no superiority in this respect over commercial samples.

\section{OPERATIVE TREATMENT OF INJURY OF THE PERIPHERAL NERVES.}

BY

J. RENFREW WHITE, M.B., F.R.C.S., Temporary Captain R.A.M.C.

Typical points of doubt and difficulty that present them. selves to the surgeon in the treatment of cases of nerve injury may be grouped under the following heads: I, How soon after the reception of the nerve injury should an operation be performed? II, What are the indications for operation as derived from the study of the signs and symptoms? III, Points of difficulty and doubt as regards correct or best procedure and technique arising during the actual operation.

\section{I.-THE INDICATIONS IN TIME FOR OPERATION.}

All wounds caused by present-day projectiles, even those prodaced by rifle and machine-gun bullets that enter and emerge through tiny slin punctures, must be regarded as infected. The complication of a nerve injury by sepsis, or the involvement of a nerve trunk in a septic inflam. matory process, appears to be fatal to that regeneration of nerve fibres which leads to and is the indispensable basis of the re-establishment of conductivity in the segment of the injured nerve and distal to it that clinically we desig. nate "recovery." Neither the reason for this nor its pathological basis is far to scek; nowadays, when so many damaged nerves are being operated on, the former is again and again made clear by, and the latter exemplified in, the excessive production of scar tissue by the infective inflammatory process. This excess of scar tissue, with the different position or positions in which it finds itself pro. duced, seems to act in different ways towards its one unfortunate end. These are as follows:

1. Scar tissue formed between the ends of a completely or incompletely anatomically divided nerve which have 